\title{
UNDERSTANDING THE CONCEPT OF GEOGRAPHIC INFORMATION SYSTEM AND MODELLING FORMALISMS
}

\author{
WEMBE SOP DIAKE HUBERT ${ }^{1}$ \\ ${ }^{1}$ Faculty of Applied Economics and Management, University of Douala - Cameroon- \\ wembesop@yahoo.com
}

\begin{abstract}
In this paper, we define the notion of geographic information system and its basic notions. We explain his interest in efficient management of in terms of geographical decisions. After having examined their form of representation, we try to present some modeling formalisms to guide decision-makers for choosing formalism adapted to their needs.
\end{abstract}

\section{KEYWORDS}

SIG, Geo-referenced maps, Modeling, Formalisms, picture.

\section{INTRODUCTION}

The information and image are essential in our daily lives. Understanding the complexity of our environment and managing efficiently requires information found in maps, plans and databases. The grouping of cards which is a database helps to understand the world by giving performances overall to remember and to consult. These cards can also transmit geographic information with messages more or less developed; these are considering as such part of the elements that combine to take a decision (Joliveau T. (2006). This article deals with the geographic information system consists of two sections. The first provides general information on the concept of geographic information system and the second provides an overview of several modeling methods.

\section{THE GEOGRAPHIC INFORMATION SYSTEMS}

\subsection{DEFINITION}

A single location, an isolated figure doesn't have sense by itself in a Geographic Information System. The information contained therein is revealed by the comparison with other locations or other data. The value of geographic information is to allow three main types of operations: the identification of the location of an object, the comparison and then the decision support. Indeed, a localized object has meaning, only with comparison to several others. Identifying the location can therefore answer a number of issues related to the spatial, object of geography: why this object here, is not there and not elsewhere? How these objects are located relative to each other and how to explain the shape of the resulting geographic distribution? 
The data management "complex" collected on changing environments, shaped and reshaped constantly by actors often elusive and often cannot be versatile that within a Geographic Information System (SIG) defined Didier and Bourveyron, C (1993) as organized set of tools (hardware), software (software), and georeferenced data that can analyze, update, and several forms, including individual, thematic and synthetic. This is an information system containing subsystems for the capture, storage, retrieval, manipulation, analysis, display of spatial data. Each subsystem has a feedback on an appropriate mechanism for quality control.

The S.I.G provides concepts, methods and tools, through computer representations of the real world, manage and synthesize geographic information. Servigne S (2006). Its originality lies in its ability to compare different entities based on their common geographic occurrence as mentioned Collet, C. (1992). However, Rimbert, S. (1990) notes that the actors who govern and animate the landscape dynamics are not reducible to formulas and codes; addition, the landscape is one dimension of social being that we can eliminate, at least for convenience Provisional Technical hence the need to detect changes on the basis of geo-referenced maps.

Always Kamar, Laurini R kilany Chamoun (2011), the card is seen as a graph on practical and theoretical elements that are situated in time and space, it is actually a support that have an image symbolizing a form of a figure handwritten printed or produced by any other means "As a restrictive, note that a simplified map is a diagram of all or part of the earth after a certain size. This definition is called synthetic mathematical concepts of projection and scale. The notion of scale necessarily implies a simplification of the overall image by generalization, the choice of the objects represented.

Servan-Courant S [2005], he georeferenced maps are intended to ensure the continuous availability of spatial information on the environment in its various forms: qualitative and quantitative.

From a qualitative standpoint, georeferenced maps seek to know the status of a landscape at a given time; they provide information about the orientation of the temporal evolution of a landscape in time and space, on distribution and evolution of the players of this dynamic. This allows making rational predictions concerning the organization and equipment. So these are appropriate comparators use by those responsible for public administration, regional and local authorities to ensure efficient management.

\subsection{REPRESENTATION}

Representation of geographical data in a geographic information system is done at two levels: semantic level and the geometric level.

\subsubsection{SEMANTIC LEVEL}

The semantic level defines the geographic entities that are modeled. For this, we must determine the structure, the stable elements and relevant information of the observed phenomenon. The reality of this phenomenon is well studied for its functional dimension (physical, economic, social rule etc...), its geographical context, its structural dimension (relationship between the entities that comprise the reality) and more by its temporal dimension (evolution over time of the phenomenon).

Geographic objects are differentiated from each other by their characteristics and relationships. Intuitively, there are many ways to group objects based on common characteristics. The reason is to define these classes of objects. The characteristics of the objects present two fundamentally 
International Journal of Computer Science \& Information Technology (IJCSIT) Vol 4, No 2, April 2012

different types: those that are intrinsic to the object (the number of a street) and those relating to an object relative to other objects (the capital of an administrative unit). According Gayte et $\mathrm{Al}$ (1997), the intrinsic characteristics of objects are called attributes; characteristics relating semantic are called relation.

\subsubsection{GEOGRAPHIC LEVEL}

For Favetta F, Laurini R (2006), the geographic level inherits a dichotomy between the vector mode and raster mode: In the vector mode, the position of objects is expressed by coordinates $(\mathrm{x}, \mathrm{y}, \mathrm{z})$ attached to a positioning reference. It is this last feature that differentiates GIS data mapping assisted by computer. The shape of the objects is expressed by means of three main geometric primitives who are: the point, the poly-line and the polygon. A point object associated with a single set of coordinates gave its position in space.

A linear object is associated an ordered sequence of coordinates. Each point in this sequence is connected to the next point by a line segment. The form of a linear object is thus translated by a broken line represents the linear phenomenon. An object surface is understood as within its contour. It is delimited by a linear object which closes on itself.

In raster mode, for Guptill and $\mathrm{Al},(1995)$, the position is expressed by the reference node in the mesh or the mesh matrix. By construction, the shape of objects is made by that connectivity of pixels bearing the same value (or range of values). Thus, pointwise results in a pixel value of another. A linear form is represented by a sequence of related pixels having the same value, each at least two neighbors' of the same rank and standing out from the surrounding pixels characterized by another value. A surface shape is also a connected set of pixels having the same value but not limited neighborhood, surrounded by pixels of another value.

These geometric shapes are defined in Euclidean space two or three dimensions. It follows that they are positioned against each other by spatial relationships. This allows accounting for the relative position of the shapes relative to each other as mentioned Genin A, Servain-Courant $S$, Yengue J L (2003), in them, the geometric shapes can be independent of each other (spatial relationships implied). This is the mode used by MapInfo. If they have arcs in common, it is the mode topology. In this mode, two arcs cannot intersect and cannot have in common apart from their ends.

Taking into account these two types of representations of geographic data, we can set up a database with a simple methodology sufficiently clear and reproducible by other researchers in environmental sciences. The guideline will be the simplicity of treatment.

The first step may consist in the definition of a framework of treatment to rebuild the base at any time, from the raw data and, if necessary, with different software. This treatment can be described precisely enough to carry them out again, even if the function used is no longer identical.

The second step is to be able to easily incorporate new data, while maintaining the consistency of the database. This involves carefully note some constants, such as retiming operations, at the beginning of string. Indeed, registration and its corollary, resembling, are operations that transform a lot of data. It is therefore safer to perform on the raw data in order to eliminate drift in subsequent treatments as noted by Killian, B. (1986). 
International Journal of Computer Science \& Information Technology (IJCSIT) Vol 4, No 2, April 2012

\subsection{DETERMINATION OF LAYERS VECTOR}

The basic principle for the determination of vector layers and each layer requires that relationship should contain only one type of object or theme and that within a relationship, there must be no overlap between the objects as noted by Cauvin, C., Raymond, H. Serradj, A. (1987). This principle is crucial since it determines the types of cards that can be achieved and, ultimately, the analyzes that can be drawn.

Grouping data with a geographic basis is a standing invitation to their comparison. Furthermore, when localized data are represented on several layers, the geographical configuration obtained provides much more information and to provide more sets. Additionally, it restores information about the neighborhoods statistical values and sometimes has a characteristic shape memorable that synthesizes a large number of local comparisons.

The Geographic Information System is organized into themes and each theme can have one or more layers of information. Each information layer consists of several objects which are attached on alphanumeric data. Each element of the map has a link that allows to query or alphanumeric display information about it.

The location is generally used as support for object attributes. The attribute information makes sense in comparison with the attributes of other locations. The comparison provides information that has more value than geographical objects considered and are qualitatively similar to priori, that is to say you expect them to have common properties.

Increasingly, geographic information is essential for all those who make decisions geographical, that is to say for the territory, whether it be local government officials, actors from the development as diverse a simple landowner. Since relations are multiplying, any action on a site may interfere with others.

Like all information that could be used by the computer, it is possible to directly model the spatial data by data structures.

\section{MODELING FORMALISM}

Whether you want to organize descriptive information like geographical or topological, semantic-rich, we need a method of representing data with mathematical descriptions adapted according Laurini R. and Millet-Raffort, F (1993). We present some of these methods used in artificial intelligence (semantic networks, production rules) and others are mixed (Objectoriented model, model hyper graphs).

\subsection{FORMALISM FROM ARTIFICIAL INTELLIGENCE}

\subsubsection{SEMANTIC NETWORKS}

The semantic networks from artificial intelligence.

In this formalism, we represent all occurrences of entities with relations that affect them.

The entities are represented by their names and relationships by arcs.

Sometimes it is also possible to make a representation of predicates are Boolean functions including use in Prolog

Example: Has (Stone, Parcel A) 
Have (stone, Parcel B)

Depends (Parcel A, City X))....

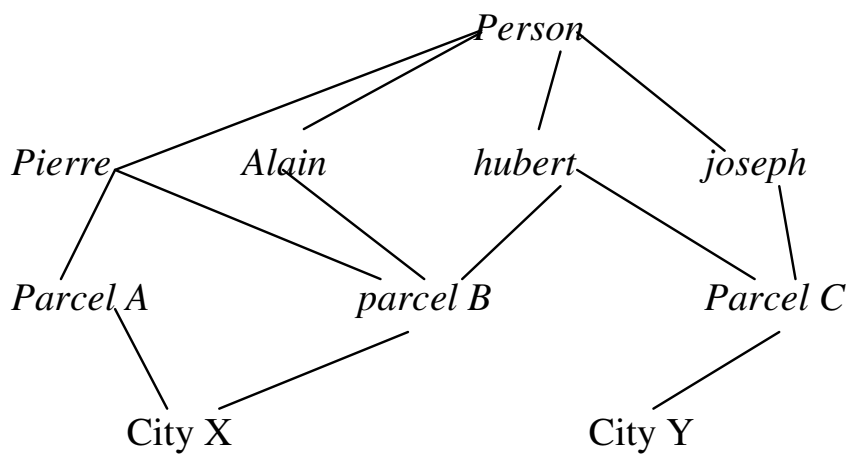

Figure 1. Exemple of diagram about semantic level

This representation provides a visualization of relationships between objects and thus allows managing the exceptions.

\subsubsection{RULES OF PRODUCTIONS}

Called production rules in a way of representing knowledge in the form:

\section{If condition then action;}

The conditions are called first fruits consequences and actions.

For example: if cold, then pull starter.

In this formalism, it has a set of rules (If-Then) which is a rule base and a basic set of facts describing a situation is called a basis of the facts. Via an inference engine (software to manipulate the rules and making inferences), it is possible to derive all consequences of the basic facts (forward chaining) or else to discover the causes that can generate these basic facts (back chaining).

Note that all production rules are well managed by all inference engines. This mechanism is more amenable to manipulation than literal geometric manipulations.

\section{2-OBJECT-ORIENTED MODEL}

From artificial intelligence (semantic network) and database (entity-relationship model), the object-oriented model to represent the objects (entities) and their classes. We then say that an object is an instance of a class.

One feature of this model is the existence of inheritance links "is one" which allow the introduction of classes in a number of properties that will be inherited implicitly by the authorities. 
In its representation, there are links between instances of classes, and links "is a" between classes or between instances and classes and sub-assemblies.

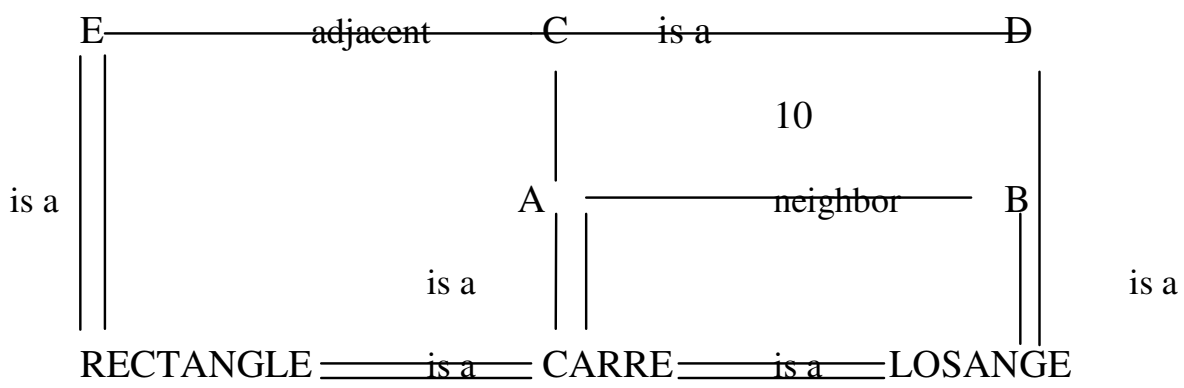

$A$ is a square

$B$ is a rhombus

$E$ is a rectangle

Figure 2. Example of spatial modeling object oriented

\subsection{MODEL IN HYPERGRAPHS (HBDS)}

The formalism HBDS (Hypergraph Based Data Structure) is based on the concepts of hypergraphs, at least in the original version developed by Fallah, S. (1994). The formalism to describe the object classes, instances, properties, property inheritance, and multiple links between objects and classes.

In his formalism, an oval embraces both the class and instances. The class is represented by a black circle and the various institutions by small squares.

The thick lines connecting the black dots represent the links between classes with the mechanism of inheritance of properties; the thin lines are the links between instances without inheritance mechanism.

This formalism has the advantages of the entity-relationship (links represent associations and can be optionally bearing properties). It reduces the semantic type models by distinguishing the links "is an" other links between classes, and avoids the multiplication of such links between instances (since they are found recorded in the class level). This model is also close to the object-oriented model.

\section{CONCLUSION}

The purpose of this discussion was to define and explain the concept of geographic information system, and some models modeling. Indeed, geographic information systems now represent the complete tool for collecting, breeding and exchange knowledge on the planet. We must stress its importance in the economic, ecological and cultural. 
International Journal of Computer Science \& Information Technology (IJCSIT) Vol 4, No 2, April 2012

\section{REFERENCES}

[1] Cauvin,C., Raymond,H., et Serradj,A (1987). Discrétisation et Représentation cartographique. Montpellier, RECLUS, Coll, « Mode d'Emploi ».

[2] Collet,C., (1992). Système d'information Géographique en mode image, Lausanne, Presses Polytechniques et universitaires romandes, Coll. «Gérer l'Environnement ».

[3] Didier,M. et Bouveyron,C.(1993). Guide économique et méthodologique des SIG, Paris, Hermès.

[4] Fallah, S. (1994). Représentation et manipulation de plans a l'aide des reseaux de pétri. Actes des 2emes Journées Francophone IAD-SMA. Voiron

[5] Gayte et Al (1997) ; Conception des systèmes d'informations sur l'environnement : ED. Hermès, Paris.

[6] Genin a., Servain-courant s., Yengue j-1 (2003) Transects de paysages et Système d'Informations Géographiques, des outils pour l'analyse des paysages, exemple du Val de Loire (Indre-et-Loire), Les rencontres du Végétal, 20-21 novembre 2003, I.N.H Angers.

[7] Guptill, S.C et Morrison, J.L (1995); Elements of spartial data quality. Oxford, Elsevier ,England.

[8] Joliveau T. (2006). Le rôle des systèmes d'information géographique dans la planification territoriale participative. Chapitre 4 in Aide à la décision pour l'aménagement du territoire. Méthodes et outils. Traité IGAT. Information Géographique et Aménagement du Territoire Paris, D. Graillot et J.-P. Waaub, Lavoisier/Hermes: 149-178.

[9] karam R., laurini R., kilany chamoun r, Favetta f., (2011) "Intégration Sémantique et Cartographique des services localisés multifournisseurs". Rvue "Cartes et Géomatique", Septembre 2011, pp. 35-49. Comité Francais de la Cartographie. 2011.

[10] Killian B,(1986). L'apport des données satellitaires dans l'établissement des cartes utilisées par le développement rural. Colloque SPOT «SPOT 1premiers résultats en vol » Toulouse, Cepadues-

[11] Laurini,R.et Milleret-Rafford,F.(1993). Les bases de données en géomantiques, Paris, Hermès.

[12] Laurini R, Favetta F (2006) Towards an Efficient Integration, Structure and Exploration of Landscape Architecture Project Information, in the proceedings of the IEEE International Conference on Multimedia \& Expo (IEEE-ICME'2006), IEEE Computer Society, Toronto, ON, Canada, July 9122006 , pp. 397-400

[13] Michelin Y., Joliveau T., et al. (2002). Guide méthodologique pour une gestion des paysages dans un projet de territoire, Chambre d'agriculture de Haute-Vienne-ENITA-CRENAM. 60 p.

[14] Pornon, H. (1992). les SIG mise en œuvre et applications, Paris, Hermès.

[15] Rimbert, S. (1990). Cartographie, Paris, Hermès.

[16] Servain-courant S, (2005) "Système d'Information Géographique et photographies, des outils pour l'analyse et la gestion des paysages ; une étude de cas en Loire moyenne", intervention à l'Ecole d'été du projet Culture 2000 Rivers as cultural infrastructure, septembre 2005, Ferrara (Italie)

[17] Servigne s. Concepts de base. Fondements des bases de données spatiales. Paris : Hermes Science - Lavoisier. 2006. Collection IGAT. Pp 21-36

Author

Dr. WEMBE SOP DIAKE computer engineer holds a Ph.D. in computer science.

$\mathrm{He}$ is currently teaching at the university of Douala Cameroon.

It provides courses on algorithms.

His research interests include information systems and networks applied to businesses on data mining. 